\title{
A Minimum Variance Hedging Ratio Model Based on Nonlinear Grey Classification Model
}

\author{
Xia Gao $\mathbb{D}$ and Zhanxing Zhao \\ School of General Education, Chongqing Institute of Engineering, Chongqing 400056, China \\ Correspondence should be addressed to Zhanxing Zhao; 00265@cqie.edu.cn
}

Received 14 January 2022; Revised 6 February 2022; Accepted 7 February 2022; Published 28 February 2022

Academic Editor: Xin Ning

Copyright (c) $2022 \mathrm{Xia}$ Gao and Zhanxing Zhao. This is an open access article distributed under the Creative Commons Attribution License, which permits unrestricted use, distribution, and reproduction in any medium, provided the original work is properly cited.

\begin{abstract}
The risk transfer function of futures market is mainly realized by hedging strategy. Futures price yield and spot price yield tend to show different fluctuations before and during hedging, which leads to the distortion of hedging ratio, that is, the calculated hedging effect is weaker than the traditional hedging effect. On the basis of MV (minimum variance) hedging model, this paper introduces NGCM (nonlinear grey classification model) to solve the nonlinear correlation between futures and spot returns, which can improve the hedging effect. The results show that, due to the existence of basis, the price change model violates the linear assumption of OLS (ordinary least squares) parameters, and there is a problem of model missetting. It is estimated that HR (hedging ratio) should choose the price model, which can better depict the linkage between futures price and spot price. The effectiveness of HR in this study is higher than that of existing models. Applying this model to hedge can effectively avoid the spot price risk. Investors can reasonably choose the hedging model according to their own needs.
\end{abstract}

\section{Introduction}

With the development of the futures market, the risk transfer function of futures contracts has been paid more and more attention, and futures contracts have been widely used for hedging in the spot market. Especially affected by the global financial crisis, Chinese enterprises are facing great threats, and the demand for avoiding risks is becoming more and more urgent, so the demand for financial derivatives by enterprises is becoming stronger and stronger [1]. Futures markets provide enterprises with future market supply and demand information, enhancing the scientific rationality of production and operation decision making, providing a place for hedging, and allowing enterprises to avoid market price risk [2]. Enterprises are increasingly paying attention to hedging transactions as a viable solution to the aforementioned issues [3,4]. Although the futures market derived transactions for the purpose of speculation and arbitrage during its development, its primary function is as a hedging tool that enables enterprises to cope with the deteriorating market environment, achieve the goal of avoiding risks and locking in costs, and ensure the healthy and stable development of enterprises [5].

Hedging by traders is actually a portfolio investment of assets in spot market and futures market. Hedgers determine the trading positions in spot market and futures market according to the expected return and variance of portfolio investment, so as to minimize the risk or maximize the utility $[6,7]$. Barbi and Romagnoli [8] applied the binary copula function with analytic parameters to the calculation of MVHR (minimum variance hedging ratio) of copper futures contracts, which simplifies the estimation of copula distribution function value, and the effectiveness of hedging is better than the traditional hedging model. In describing the correlation of variables in MV (minimum variance) hedging, the traditional linear correlation coefficient can no longer meet the requirement of accurately describing the nonlinear and dynamic correlation between variables. Therefore, when calculating MVHR, a great deal of research has been done on time-varying parameter methods and some nonlinear correlation indicators, and many achievements have been made $[9,10]$. The correlation measure derived from the pair copula 
model can well capture the information of nonlinear correlation between two variables in high-dimensional assets. So far, there is no empirical evidence to prove that the research results of $\mathrm{MV}$ hedging theory can guide the practice of enterprises, showing the phenomenon that MV hedging theory deviates from hedging practice [11].

The primary issue at hand is determining the phase relation number. The Pearson correlation coefficient is the measurement of correlation coefficient in all existing models. Only the linear correlation between variables is taken into account by the Pearson correlation coefficient. When the futures or spot markets fluctuate significantly, a nonlinear relationship often emerges, resulting in hedging failure [12]. This paper analyzes NGCM (nonlinear grey classification model) and tries to find a model suitable for estimating HR (hedging ratio) in Chinese enterprises, which is of great importance to the hedging operation of Chinese enterprises, based on the serious deviation between MVHR research and practice, combined with the practical purpose of enterprise hedging.

\section{Related Work}

Constructing the MV hedging model based on copula technology is to optimize the model from the correlation between variables. The dependency structure constructed by copula function captures nonlinear information and at the same time integrates the analysis of correlation degree and correlation pattern. Hess [13] constructed a MV hedging model based on the copula function, captured nonlinear information in correlation by the copula function, and verified the effectiveness of the model. Billio et al. [14] introduced the concept of portfolio into hedging and held that futures market is an investment market, and the purpose of hedgers entering futures market is to obtain the highest returns under certain risks. Liu et al. [15] put forward the optimal HR, and since then, the determination of HR and the measurement of hedging performance have aroused the upsurge of theoretical and empirical research. On the premise of maximizing the utility function, Bodnar et al. [16] gave the calculation method of $\mathrm{HR}$, and the result is the HR with maximized utility. In [17], in order to eliminate the sequence correlation of residual terms and increase the information content of the model, that is, aiming at the residual sequence correlation of OLS (ordinary least squares) model, a bivariate vector autoregressive model was proposed to calculate HR. Singh [18] proposed an error correction model to eliminate the cointegration relationship between series and at the same time considered the long-term equilibrium relationship and short-term adjustment relationship between spot price and futures price. Lai et al. [19] found that the dynamic hedging strategy based on the GARCH (autoregressive conditional heteroskedasticity model) model is superior to the traditional constant static hedging strategy.

Scholars continue to use foreign scholars' methods in static model research, but the majority of them use the OLS calculation method. To test OLS and create a revised model, Robiyanto et al. [20] used the CSI 300 simulation contract
[21]. Canyakmaz et al. [22] conducted an empirical study of China's copper futures market hedging performance. Matic et al. [23] conducted an empirical study on Shanghai and Shenzhen 300 stock index futures, comparing the hedging performance of the above static and dynamic models. The cointegration relationship of spot price series has an impact on HR calculation, according to reference [24]. The basisprofit-seeking hypothesis is stated in reference [25], which states that the difference in basis between futures and spot is the basis for investors to hedge, and that hedging is done on the basis of maximizing profits, while emphasizing that all investment behaviors of investors are for the pursuit of interests. The basis for determining HR, according to reference [22], is to make Sharpe ratio optimal, and it proposes that HR be determined on the basis of maximizing hedging utility. Matsumoto [26] confirmed the OLS model's suitability for hedging as well as the fact that the HR obtained by a simple linear regression model is lower than that obtained by a traditional one and improved the model and hedging method. However, the OLS model is still based on a set of assumptions that ignore autocorrelation and heteroskedasticity of residual series, as well as time series cointegration. Auxilia and Vishwanath [27] improved the OLS model by including an error correction term and removing the influence factor of cointegration, resulting in a more accurate HR. The HR hedging performance determined by ECM (error correction model) was found to be better than the OLS model.

\section{Research Method}

3.1. Principle of HR Determination. Futures market can avoid the risks caused by price fluctuation in spot market. This function is mainly realized through futures hedging. Avoiding risk is not eliminating risk, but the risk of price fluctuation in spot market exists objectively. Generally, manufacturers, processors, and sellers are engaged in hedging, and the risks they remove through hedging are usually borne by those "speculators." Futures market can speculate the price changes of goods in the spot market in the future and find out their future prices. Because the futures market is similar to a perfectly competitive market, it trades through open bidding, and the prices generated in this case are representative, open, continuous, and predictable.

Specifically, hedging specifically refers to hedgers who hold spot assets or commodities buying and selling futures contracts with similar value and time. Hedging is a trading strategy that involves establishing profit and loss hedging channels in the spot market to protect against price fluctuations. Stock index futures hedging essentially converts the unilateral rising or falling risk of the spot stock market into the basis risk, with less risk shared between the spot and futures markets. Hedging is when you combine futures and spot risk hedging. Hedging is primarily used to offset the risk of a loss in the spot market with a profit in the futures market. Hedging is a "futures trading method" that is used to protect the value of spot assets.

Obviously, the hedger is the institution and individual that turns away the spot price risk through the futures 
market. Generally speaking, they have the following characteristics:

(1) They face a significant price risk in production or investment, which will have a negative impact on his profits.

(2) Remove risks through futures trading.

(3) When trading, the contract position you own is long and the trading direction is certain.

(4) Hedging mainly involves institutions and individuals with abundant capital.

Hedging should meet the following conditions:

(1) The variety and quantity of the selected futures contracts are roughly equivalent to the value of the spot market. Usually, affected by supply and demand, the prices of spot and futures of similar varieties will have a strong correlation, and the trend and range of price changes are generally consistent.

(2) The futures position you choose should be the opposite of the spot position you own or a substitute that will be traded in the spot market. There are long positions and short positions in the spot market. If you already own assets or physical objects or buy them at a certain price at a certain time in the future, then this enterprise is a long position in the spot market. At this time, enterprises should carry out short trading in the futures market to achieve hedging, that is, short selling in the futures market.

(3) The time of holding futures positions should correspond to the time of risk exposure in the spot market. When enterprises no longer face price risks in the spot market, they should not hold positions in the futures market and close or deliver them. If an enterprise's position in the spot market has ended, but its position in the futures market remains, its future positions will become a speculative position.

Hedging's central problem is determining the optimal HR, and the hedging rate has a direct impact on the effect of hedging. As a result, choosing the appropriate HR is a key problem for investors in the risk hedging process in order to achieve the goal of avoiding risks and obtaining certain benefits.

There are two purposes for investors to hedge, one is to prevent assets from losing due to market price fluctuations, and the other is to reduce the high risks they face as much as possible by hedging when making high-risk investments.

If the spot yield is $\Delta S_{t}$, the futures yield is $\Delta F_{t}$, and HR is $h$, then the portfolio yield after hedging is $R$; then:

$$
R=\Delta S_{t}-h \Delta F_{t} .
$$

The variance formula is as follows:

$$
\begin{aligned}
\operatorname{Var}(R)= & \operatorname{Var}\left(\Delta S_{t}\right)+h^{2} \operatorname{Var}\left(\Delta F_{t}\right) \\
& -2 h \operatorname{cov}\left(\Delta S_{t}, F_{t}\right) .
\end{aligned}
$$

Finding the optimal solution $h$ makes the variance of the combined rate of return the smallest, so we derive the two sides of formula (2) with respect to $h$ as follows:

$$
\frac{\partial \operatorname{Var}(R)}{\partial h}=2 h \operatorname{Var}\left(\Delta F_{t}\right)-2 \operatorname{cov}\left(\Delta S_{t}, \Delta F_{t}\right) .
$$

Make the first derivative zero:

$$
h=\frac{\operatorname{cov}\left(\Delta S_{t}, \Delta F_{t}\right)}{\operatorname{Var}\left(\Delta F_{t}\right)} .
$$

Because the principle of risk minimization is easy to understand and calculate, most investors calculate the optimal hedging based on this principle.

The principle of determining the optimal HR is to determine the HR based on the construction of investment portfolio. The difference between $h$ under the condition of maximizing utility and $h$ under the condition of minimizing risk lies in the investors' pursuit of income. Under the premise of maximizing utility, the hedger will flexibly adjust the holding position ratio of futures according to the expectation of future futures prices in addition to maintaining value.

The purpose of investors' pursuit of risk minimization is emphasized in this paper's HR research, which is based on risk avoidance. The principle of risk minimization determination emphasizes the purpose of investors' pursuit of risk minimization. The lower the fluctuation degree, the smaller the variance, and the obtained HR is the optimal ratio when analyzing the fluctuation degree of the hedged rate of return and comparing the variance of the rate of return to determine $\mathrm{HR}$.

\subsection{Error Analysis of $M V$ Hedging Model. If} $\left\{y_{t}: t=0,1, \ldots\right\},\left\{x_{t}: t=0,1, \ldots\right\}$ is two $I(1)$ processes, if there is such $\beta(\beta \neq 0)$ that $y_{t}-\beta x_{t}$ is a $I(0)$ process, we say $y, x$ is cointegration and $\beta$ is cointegration parameter. Cointegration refers to the long-term stable relationship between two variables.

The OLS model is based on stable data, so for unstable variables, if used directly, there will be false regression, false regression, and other problems, but for the following cases: if both processes are $I$ (1), but the linear combination of them is $I(0)$, the regression of one sequence to another sequence is not false regression but tells us that there is a long-term equilibrium relationship between them, so the OLS model can be used [16].

What matters to hedgers is how many units the spot price will change for every unit of futures price change, which is what HR stands for. To put it another way, if the data used meet assumptions 1, 2, and 3, the HR estimated by the OLS model can meet the needs of hedgers, which is consistent with the existing HR estimated by various models. In extreme cases, if the spot price does not change much during the hedging period, the spot price may even change in the opposite direction [7]. It demonstrates that the range of spot changes affects HR and thus the hedging effect, which is in line with the hedging theory. The price model, price change model, and price change rate model are the three basic models for estimating HR. The economic and metrological characteristics of econometric models are usually used to evaluate them. In summary, econometric models have two types of research problems: the first is decision- 
making or forecasting problems and the second is hypothesis testing.

This paper holds that if researchers pay attention to decision making or prediction, the regression coefficient of the model should reflect the real economic relationship between two variables as accurately as possible, and the coefficient of independent variables should be related to decision-making problems. If researchers are concerned about hypothesis testing, they should pay more attention to the measurement characteristics of the model, as shown in Figure 1.

From the correlation between regression coefficient and decision making, the regression coefficient $\beta$ estimated by the price model reflects the ratio of current and future price changes, namely, HR, while the economic significance of the regression coefficient estimated by the price change model is the ratio of current and future price changes. The price change model uses the change of futures price to explain the change of spot price, and there is no necessary connection between the relationship between futures and spot price changes and the price level [16].

3.3. Nonlinear Grey Classification Model. The goal of MV hedging is to achieve hedging by canceling futures and spot price returns mutually and reducing portfolio variance. When calculating the correlation coefficient between spot and futures returns, this mutual cancellation is taken into account. The median correlation coefficient measures the correlation between futures and spot returns that are above and below the median level, allowing for better hedging. The first is decision-making or forecasting problems, and the second is hypothesis testing in econometric models.

According to copula's related theory, for the median correlation coefficient, let $u=v=0.5$, and get [6]

$$
\rho^{*}=4 C(0.5,0.5)-1 \text {. }
$$

The NGCM is used to predict the variance of spot yield, which solves the problem of distortion of hedging effect caused by structural change of yield fluctuation in historical period and hedging period.

$$
h=\tau\left(\frac{\sigma_{s}}{\sigma_{f}}\right) .
$$

The MV hedging model of formula (6), firstly, reflects the nonlinear correlation between futures and spot price changes through the nonlinear correlation coefficient $\tau$ and embodies the essence of matching futures and spot price changes of MV hedging model; second, by predicting the standard deviation $\sigma_{f}$ of futures yield and the standard deviation $\sigma_{s}$ of spot yield, hedging has the characteristics of follow-up and real-time change.

The correlation coefficient refers to the relative difference between the $i$ th evaluation data series and the standard data series in the corresponding $k$ index, which is the core of the nonlinear grey classification model.

$$
\xi_{0 i}=\frac{\Delta_{\min }+p \circ \Delta_{\max }}{\Delta_{0 i}(k)+p \circ \Delta_{\max }},
$$

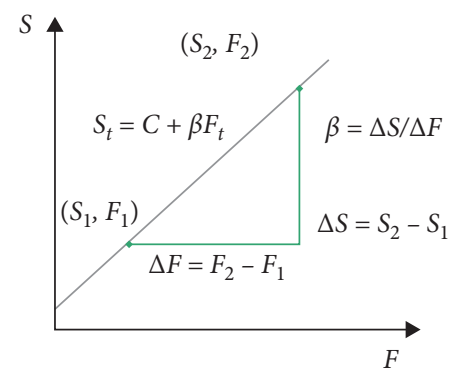

Figure 1: Economic significance of price regression coefficient of model.

where $\Delta_{\min }=\min _{i=1, \ldots, 4} \min _{k=1, \ldots, 3}\left|x_{0}(k)-x_{i}(k)\right|$ is the minimum difference of two levels; $\Delta_{\max }=\min _{i=1, \ldots, 4} \min _{k=1, \ldots, 3}\left|x_{0}(k)-x_{i}(k)\right|$ is the maximum difference of two levels; $\Delta_{0 i}=\left|x_{0}(k)-x_{i}(k)_{i=1, \ldots, 4, k=1, \ldots, 3}\right|$ is the absolute value of the $k$ th index difference corresponding to the standard data sequence and the $i$ th participating data sequence; $p$ is the resolution coefficient; and the value interval is $[0,1]$. Relevant research shows that $p=0.5$ has higher resolution.

$R_{s}, R_{f}$ is used to represent the return rate of portfolio before and after hedging, $r_{e}$ is the risk-free return rate faced by investors in a specific period, and $\sigma_{s}, \sigma_{f}$ is the standard deviation of return rate of portfolio before and after hedging.

Therefore, the ratio $H_{s}$ of unit risk return before and after hedging can be expressed as

$$
H_{s}=\frac{\left(R_{f}-r_{e}\right) / \sigma_{f}}{\left(R_{s}-r_{e}\right) / \sigma_{s}},
$$

where $H_{s}$ represents the ratio of unit risk return before and after hedging. The larger $H_{s}$, the better the hedging effect; otherwise, the opposite is true.

Figure 2 shows the principle of the NGCM-based prediction model.

In practice, most of the financial time series data have the characteristics of "volatility clustering," that is, the variance of residual series often changes with time. However, static hedging models all assume that the variance of residual sequence is constant, which is different from practice.

The majority of studies on dynamic hedging models show that the traditional static hedging model is inadequate for hedging practice. The conditional variance and conditional covariance of error terms are not constant for most financial time series data, and there are many parameters to estimate in the model. To simplify the model, the coefficient matrix is assumed to be a diagonal matrix, the conditional variance correlation coefficient is constant, and conditional variance and conditional covariance are only dependent on the lag term of their respective lag term and residual square.

\section{Result Analysis and Discussion}

What is traded in the futures market is uncertain factor in the future, so the futures market is inherently ahead of schedule, which is equivalent to the expectation of the spot market. In terms of information efficiency, the transmission 


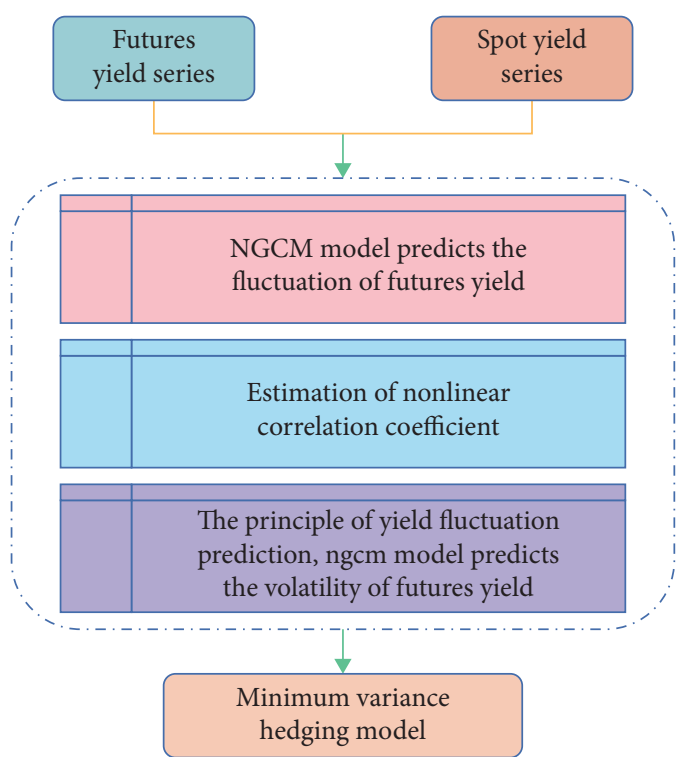

FIGURE 2: NGCM-based prediction model.

speed of futures is much faster than that of the spot stock market. Coupled with the advantages of the trading system, the price of stock index futures has the function of price discovery. For example, if the opening time of stock index futures is fifteen minutes earlier than the stock market, the opening price of stock index futures will give the stock market a certain directional guidance.

Stock index futures can also replace the buying and selling of stocks, which is an effective means of asset allocation. For example, if investors expect that the stock index will rise in the next few months, they can buy stock index futures contracts in the coming months in advance, so as to achieve the purpose of asset allocation in advance and reduce the actual buying cost.

In order to study the nonlinear relationship of spot price changes and the influence of spot price changes on HR during the inspection period, this paper selects copper futures from Shanghai Futures Exchange as the research object.

According to the actual hedging strategy, the continuous period and spot price series with two-week, four-week, and twelve-week hedging period are constructed. In order to minimize the basis risk, the principle of selecting futures contracts is to ensure that the selected contracts are the contracts with the earliest maturity after the hedging end date. In this paper, the series is divided into five groups according to the absolute value of spot price changes, as shown in Figures 3 and 4 to save space.

It can be seen from Figures 3 and 4 that with the increase of hedging cycle, the fluctuation range of spot and futures has increased significantly in both Group 1 and Group 5. The mean test of the first group of $|\Delta S|,|\Delta F|$ in the same period rejected the hypothesis of equal mean, but the hypothesis of equal mean of the fifth group could not be rejected. However, when $|\Delta S|$ increases, the influence of the change of basis on the difference of $|\Delta S|,|\Delta F|$ decreases, and the mean value of $|\Delta S|,|\Delta F|$ no longer shows significant difference.
The settlement guarantee system refers to the funds deposited by settlement member units to the exchange to prevent emergency funds in case of unexpected events. If the deposit is insufficient due to the time of warehouse wear, the settlement guarantee can be used for emergency. The settlement guarantee is equivalent to the second firewall of futures trading. The first firewall is the deposit paid by customers. When the first firewall encounters a crisis, the settlement guarantee plays a vital role as the second firewall.

Figure 5 reports the estimated results of the price model. The estimated results show that there is no significant difference in HR between different groups in the same hedging cycle, and the HR of each group in different hedging cycles is close to 1 , and there is no significant difference in regression coefficient between different groups.

It shows that the price model's estimated result has a significantly lower error than the price change model 10 , which can more accurately reflect the link between the futures and spot prices. Stock index futures' reasonable pricing and forced convergence at maturity have laid a strong foundation for hedging and other functions. The contract matures smoothly, the delivery rate is low, the main contract is switched smoothly, and the maturity date does not fluctuate abnormally. The spot arbitrage operation has greatly improved the correlation between the spot index and futures, particularly in unilaterally falling markets. The futures index's hedging and spot arbitrage strategy not only improved the spot correlation but also reduced the range volatility of the spot index, thus performing a dual role of maintaining value and stabilizing the stock market.

According to the severity of the change range, this paper divides the sample data into three stages by year: 2014-2015, 2016-2018, and 2019-2020, and makes a statistical description of the divided three subsamples. At the same time, the correlation of spot price and the correlation of spot price changes in three stages are tested, and the results are shown in Figure 6.

Figure 6 shows that the mean value of $|\Delta S|$ in three stages has significant differences in different periods, among which the period of 2016-2018 is the largest and the period of 20142015 is the smallest, indicating that the spot price changes most drastically during 2016-2018. Futures price is the expectation of future spot price. When all of the characteristics of futures are considered, it can be said that futures guide spot price and that the futures price discovery function is faster than the spot market, which is due to the high volatility of the futures market. When the market price falls sharply unilaterally, the futures price may be the first to be reflected. The hedger can expect to sell a certain contract in the futures market before the risk event occurs. After a certain period of time, if the spot stock price falls, investors can choose to reverse the short position in the futures market or choose to hold future positions until cash delivery.

Finally, the price model and the price change model are used to estimate the HR of the three subsamples, respectively (see Figures 7 and 8).

The estimation results in Figures 7 and 8 show that the regression coefficient of the price change model will be affected by the fluctuation range of spot price, which will 


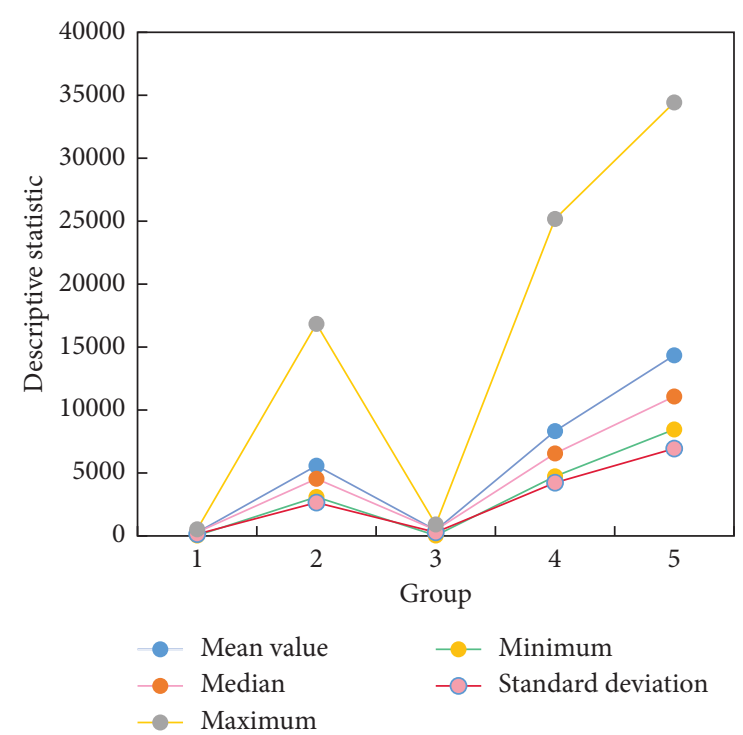

Figure 3: Descriptive statistics grouped by absolute value of spot price changes $(|\Delta S|)$.

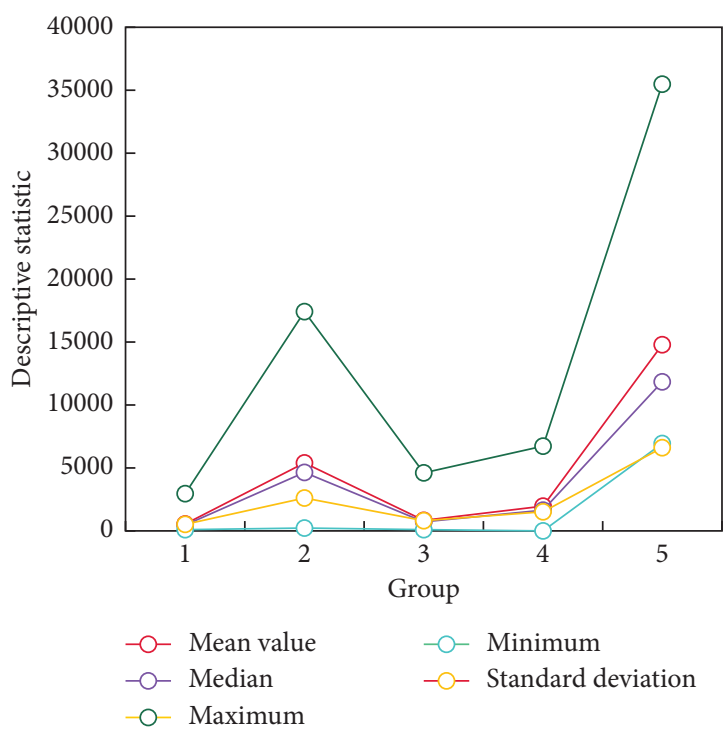

FIGURE 4: Descriptive statistics grouped by absolute value of spot price changes $(|\Delta F|)$.

increase with it. Also, the price model is less influenced by $|\Delta S|$, which can better reflect the linkage relationship between futures price and spot price, which is consistent with the previous assumption.

According to formula (8), the hedging effect of HR of each model is measured by out-of-sample data, so as to obtain the optimal hedging model corresponding to the outof-sample data based on risk minimization, so as to check whether the optimal hedging model and ratio obtained from the data inside and outside the sample are consistent (see Figure 9).

The hedging effect $H_{e}$ of the optimal HR of the four models is above $90 \%$, which indicates that the optimal HR obtained from the in-sample data is still applicable to the out-

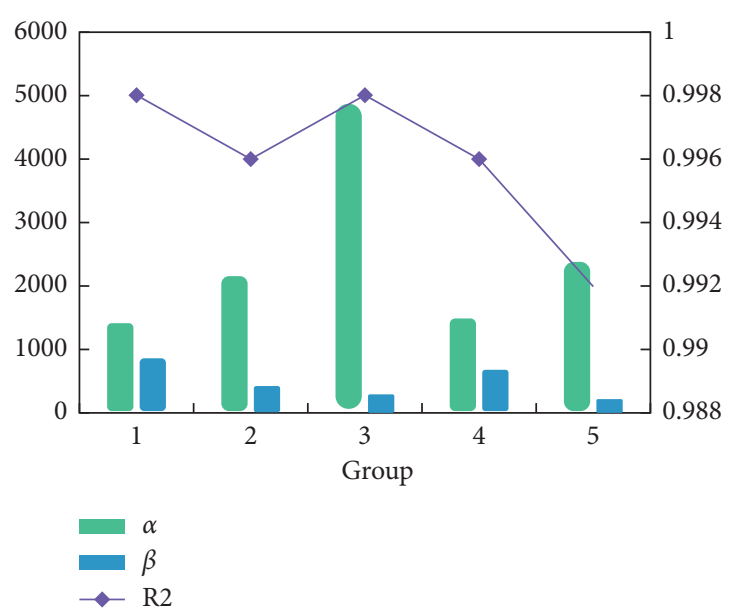

Figure 5: Model regression estimation results.

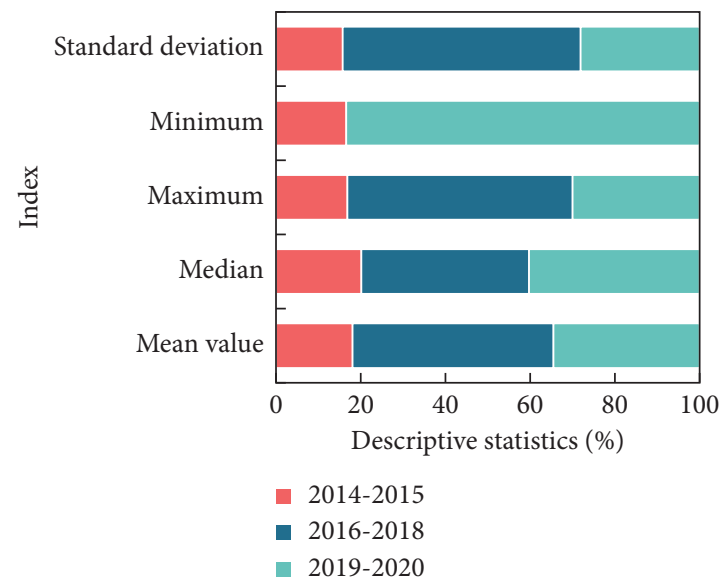

FIgURE 6: $|\Delta S|$-staged descriptive statistics of twelve-week hedging period.

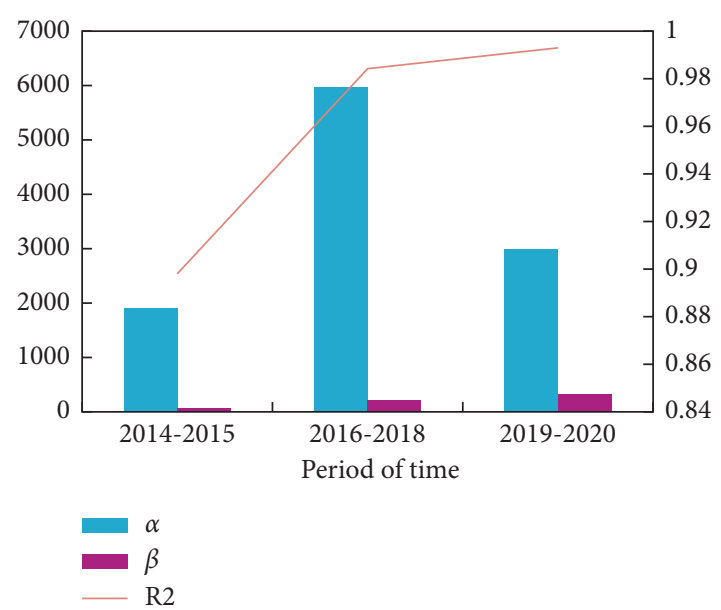

FIGURE 7: The estimated result of price stepwise regression model.

of-sample data, and the hedging effect of HR obtained from the in-sample data has a certain continuity to the out-ofsample data. It shows that the HR obtained by the four models is highly predictive for future applicability, which further 


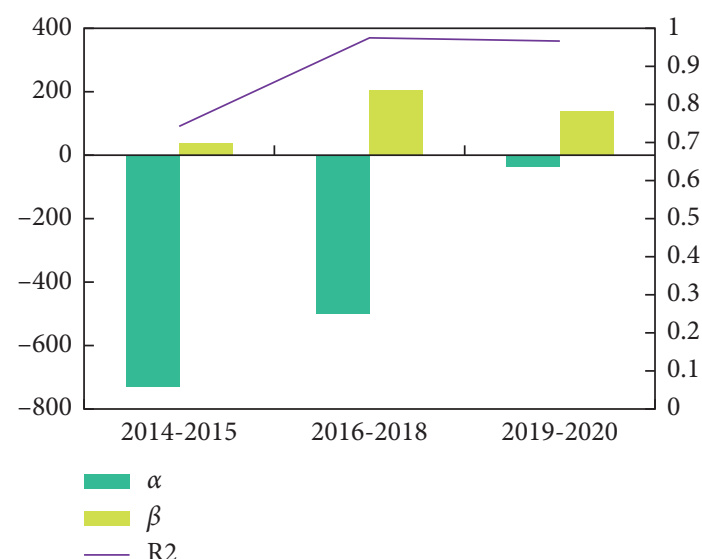

FIGURE 8: Estimate result of stepwise regression of price change model.

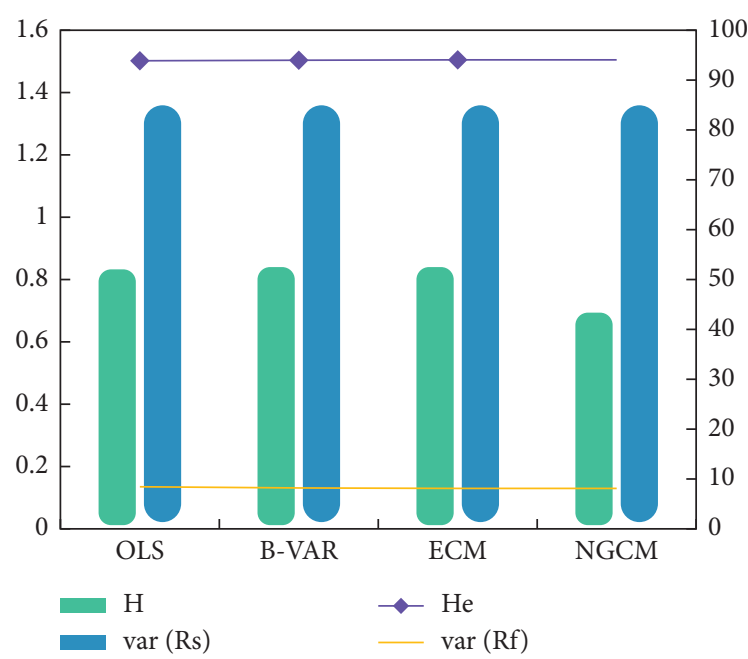

FIGURE 9: Statistics of futures hedging effect.

shows that the research on futures HR of Shanghai Futures Exchange in this paper has certain practical applicability.

Under the principle of risk minimization, the NGCM is the best model of futures hedging in Shanghai Futures Exchange, followed by dynamic ECM. Therefore, if investors pursue risk minimization, NGCM and dynamic ECM can be used to hedge futures in Shanghai Futures Exchange.

Hedgers' positions in the futures and spot markets must be the polar opposites of mutual hedging, i.e., the principle of opposite directions. Because the purpose of hedging is to prevent external situation changes that may be unfavorable to investors' assets in the future, it is necessary to form a hedging pattern when establishing futures hedging positions: if the situation changes in the future, the reverse settlement profit of future positions will be used to compensate for losses suffered by spot positions. The most important principle of futures hedging is this.

\section{Conclusion}

The nonlinear correlation coefficient is used to replace the linear correlation coefficient of the traditional minimum variance hedging ratio model in this study, which improves the model's calculation accuracy and ensures the correlation coefficient's calculation accuracy when the futures price and spot price fluctuate greatly. The closer the HR is to 1 , the more drastic the spot price changes, indicating that $|\Delta S|$ will affect the HR estimated by the price change model but has no effect on the price model. The empirical findings show that the price model accurately reflects the relationship between futures and spot prices. For hedging, investors can choose between the NGCM and the dynamic OLS model if they want to maximize unit risk and return. We should improve hedge investor education and awareness, treat hedging rationally, and avoid using hedging to make speculative profits.

However, as people's behavioral finance research deepens, the adjustment of trading mechanisms and the influence of investor sentiment on hedging effect are gradually excavated and revealed, so the introduction of trading mechanism and investor sentiment is the future research direction of hedging.

\section{Data Availability}

The data used to support the findings of this study are included within the article.

\section{Conflicts of Interest}

The authors declare that they have no conflicts of interest.

\section{References}

[1] D. Chun, H. Cho, and J. Kim, "Crude oil price shocks and hedging performance: a comparison of volatility models," Energy Economics, vol. 81, pp. 1132-1147, 2019.

[2] D. Hainaut and F. Moraux, "Hedging of options in presence of jump clustering," Journal of Computational Finance, vol. 22, no. 3, pp. 1-35, 2018.

[3] J. Li, "Optimal hedge ratios based on Markov-switching dynamic copula models," Journal of Risk, vol. 20, no. 6, pp. 55-74, 2018.

[4] C. Burgard and O. Torne, "Efficient pricing and super-replication of corridor variance swaps and related products," The Journal of Computational Finance, vol. 21, no. 4, pp. 79-96, 2018.

[5] E. Su, "Stock index hedging using a trend and volatility regime-switching model involving hedging cost," International Review of Economics \& Finance, vol. 47, pp. 233-254, 2017.

[6] N. Ke, T. F. Coleman, and Y. Li, "Learning sequential option hedging models from market data," Journal of Banking \& Finance, vol. 133, no. 1-2, Article ID 106277, 2021.

[7] H. Li, "Dynamic hedging of longevity risk: the effect of trading frequency,” Astin Bulletin, vol. 48, no. 1, pp. 1-36, 2017.

[8] M. Barbi and S. Romagnoli, "Skewness, basis risk, and optimal futures demand," International Review of Economics \& Finance, vol. 58, pp. 14-29, 2018.

[9] K. Hassan, A. Hoque, and D. Gasbarro, "Separating BRIC using Islamic stocks and crude oil: dynamic conditional correlation and volatility spillover analysis," Energy Economics, vol. 80, pp. 950969, 2019. 
[10] F. Papailias, D. D. Thomakos, and J. Liu, "The baltic dry index: cyclicalities, forecasting and hedging strategies," Empirical Economics, vol. 52, no. 1, pp. 255-282, 2017.

[11] A. Chen, E. Pong, and Y. Wang, "Accessing the China A-shares market via minimum-variance investing," The Journal of Portfolio Management, vol. 45, no. 1, pp. 106-117, 2018.

[12] S. Y. Hong, O. Linton, and H. J. Zhang, "An investigation into multivariate variance ratio statistics and their application to stock market predictability," Journal of Financial Econometrics, vol. 15, no. 2, pp. 173-222, 2017.

[13] M. Hess, "Minimal variance hedging in multicurve interest rate modeling," Lithuanian Mathematical Journal, vol. 59, no. 3, pp. 338-356, 2019.

[14] M. Billio, R. Casarin, and A. Osuntuyi, "Markov switching GARCH models for Bayesian hedging on energy futures markets," Energy Economics, vol. 70, pp. 545-562, 2018.

[15] P. Liu, D. Vedenov, and G. J. Power, "Is hedging the crack spread no longer all it's cracked up to be?" Energy Economics, vol. 63, pp. 31-40, 2017.

[16] T. Bodnar, S. Mazur, and Y. Okhrin, "Bayesian estimation of the global minimum variance portfolio," European Journal of Operational Research, vol. 256, no. 1, pp. 292-307, 2017.

[17] R. Zainudin, "The effect of regime shift in minimum variance hedging ratio: the evidence of the crude palm oil market," Investment Management \& Financial Innovations, vol. 10, no. 4, pp. 83-92, 2017.

[18] G. Singh, "Estimating optimal hedge ratio and hedging effectiveness in the NSE index futures," Jindal Journal of Business Research, vol. 6, no. 2, pp. 108-131, 2017.

[19] Y. Lai, W.-S. Chung, and J. Chen, "Hedging performance and the heterogeneity among market participants," Studies in Economics and Finance, vol. 36, no. 3, pp. 395-407, 2019.

[20] R. Robiyanto, B. A. Nugroho, E. Handriani, and A. D. Huruta, "Hedge effectiveness of put replication, gold, and oil on ASEAN-5 equities," Financial Innovation, vol. 6, no. 1, p. 29, 2020.

[21] R. Lu and C.-H. Chou, "Currency risk hedging for US stock and bond investment from Taiwan perspective," Special Issue of Insurance, vol. 35, no. 3, pp. 229-244, 2019.

[22] C. Canyakmaz, F. Karaesmen, and S. Özekici, "Minimumvariance hedging for managing risks in inventory models with price fluctuations," Foundations and Trends in Technology Information and Operations Management, vol. 11, no. 1-2, pp. 107-123, 2017.

[23] J. L. Matic, N. Packham, and W. K. Hrdle, Hedging Cryptocurrency Options, MPRA Paper, Munich, Germany, 2021.

[24] L. Benada, "Linear hedging of crude oil and natural gas," International Journal of Trade and Global Markets, vol. 11, no. 4, pp. 323-333, 2018.

[25] Y. Hou and M. Holmes, "Do higher order moments of return distribution provide better decisions in minimum-variance hedging? Evidence from US stock index futures," Australian Journal of Management, vol. 45, no. 2, pp. 240-265, 2019.

[26] K. Matsumoto, "Mean-variance hedging with model risk," International Journal of Financial Engineering, vol. 04, no. 4, Article ID 1750042, 2017.

[27] P. Auxilia and G. Y. Vishwanath, "Hedging effectiveness analysis of high market cap Indian stocks using OLS and GARCH hedge ratios," Global Journal of Management and Business Research, vol. 17, no. 3, pp. 23-30, 2017. 